\title{
Timing Contributions To State Educational Savings Plans
}

\author{
Kemper W. Moreland, (E-mail: kmoreland@emich.edu), Eastern Michigan University
}

\begin{abstract}
State educational savings plans have become increasingly popular with families saving for college because contributions grow tax free. Many states also allow contributions to be deducted under the state income tax but with an annual limit. This state tax subsidy creates a dilemma for moderately wealthy investors: contribute a large sum now or limit this year's contribution to free funds for future annual deductions? This study calculates how tax rates, time horizons, and rates of return determine one's choice.
\end{abstract}

\section{Introduction}

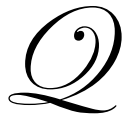

ualified Tuition Plans have been growing in popularity, particularly state education savings plans, SESP. ${ }^{1}$ In many ways these savings plans, also called 529 plans, act like Roth IRAs: money contributed into these plans cannot be deducted from federal personal income taxes, but these savings can grow untaxed, including tax-free withdrawals. To qualify as a tax and penalty free withdrawal under the SESP, of course, the money must be spent on higher education expenses for the plan's beneficiary. The government has included a very generous definition for higher education expenses, including room and board. These state plans allow large annual contributions. Currently Roth IRAs face an annual limit of $\$ 3000$ per contributor ( $\$ 3500$ if over 50). Most state education plans have a contribution limit over $\$ 200,000$. This high limit applies to the total investment no matter when the contributions are made. If the limit were $\$ 200,000$, you could contribute $\$ 200,000$ now or make smaller contributions over several years. ${ }^{2}$ Once your plan's value rises to more than the limit, you cannot make additional contributions. This study compares a large upfront investment to a more constant stream of contributions while taking into account state and federal tax implications.

At first placing the money as early as possible into the SESP seems desirable. It appears obvious that we would like all of our available investments to compound tax-free. This conclusion becomes less obvious, however, for those living in the many states that allow a limited deduction under the state income tax. If you place all of your available funds of $\$ 50,000$ into a SESP today, for example, but your state limits the annual deduction to $\$ 10,000$, then you will have no funds available to get a state deduction next year. Burman, Gale, and Weiner (2001), and other studies have described the trade-offs between Roth and traditional IRAs. A recent study by Davis (2002) examined the complex maze of choices created by federal tax credits, grants, and 529 plans, but little attention has been devoted to the contribution-timing choice created by these educational savings plans.

A few states have no limit on annual deductions but place a limit on lifetime contributions. In this instance placing your funds immediately into the state plan would be desirable, or at least until your taxable income becomes zero. People who live in states that do not allow any deduction or that have no state income tax will wish to contribute all of their funds now also. If one has little wealth and cannot save more than the state deduction, the choice between contributing today versus tomorrow becomes irrelevant. The interesting problem lies with those people with moderate to substantial wealth living in states with a limited deduction for contributions. These people face the choice between earning tax-free interest on a large contribution now or maximizing the value of state deductions by making smaller annual contributions. We study this choice. 


\section{General Problem}

In this study we shall set up a stylized example to delineate the important parameters to consider in timing contributions. We shall assume that we have an investor with wealth that rises far above the current annual deduction. This investor has a need to save for his or her child's education. The state in which this investor resides has a lifetime contribution limit beyond the wealth of the investor but with a current annual deduction well below the money available to invest. The following variables will play a role in our investor's decision.

$\mathrm{S}=$ Total sum of money to invest.

$\mathrm{T}=$ Number of years until the money will be needed.

$\mathrm{D}=$ State's annual maximum deduction.

$\mathrm{t}_{\mathrm{S}}=$ State marginal tax rate faced by the investor.

$\mathrm{t}_{\mathrm{F}}=$ Federal marginal tax tate faced by the investor.

$\mathrm{r}_{\mathrm{S}}=$ Gross (and net) rate of return to investments in the state plan.

$\mathrm{r}_{\mathrm{M}}=$ Gross rate of return to market investments not held in the state plan

One may be attracted or driven away by a state plan that earned a rate of return different from market investments. Generally these state savings plans have a variety of investments available including a broad collection of bonds, stocks, or a balanced fund. Typically in the balanced fund the plan automatically adjusts the mixture of bonds and stocks based on the age of the beneficiary. Given the broad range of market assets available we assume that $\mathrm{r}_{\mathrm{S}}=\mathrm{r}_{\mathrm{M}}$.

We make the convenient assumption that the investor currently has just enough money to make the maximum state deductible contribution each year until he needs the money: $S=T \cdot D$. Our consumer will be comparing two investment strategies: (1) contribute D dollars per year for T years, or (2) contribute all of S to the state plan now. This study will determine which of these two choices will lead to the greater sum of money in $\mathrm{T}$ years. $^{3}$

The amount of money one accumulates over $\mathrm{T}$ years depends not only on the variables listed above and the choice one makes, but also on whether one chooses to itemize one's federal tax return. Reducing state taxes by contributing to a SESP also reduces the state income tax deduction allowed by the federal tax system for those who itemize. Thus, we must account for this reduced federal deduction for itemizers but not for those taking the standard deduction.

For those choosing to spread out their contributions over T years we must account for the after-tax returns to monies not yet contributed. Suppose we have $S=\$ 50,000$ to invest, and we have a $T=5$ year time horizon. If we contribute $\$ 10,000$ today $(\mathrm{t}=0)$ to the state plan, we still will have $\$ 40,000$ that initial year earning a market return subject to state and federal taxes. After contributing another $\$ 10,000$ in the following year $(t=1)$ we will now have $\$ 30,000$ earning a taxed return for a year. In the year just before we need the money, the last $\$ 10,000$ will be contributed to the state plan. ${ }^{4}$

\section{The Formulas}

First, consider putting the funds into the private market without any tax advantages. In this case all returns on our principal will be subject to federal and state income taxes. The final dollar return will also depend on whether the investor itemizes or does not itemize. For those who itemize the value of putting $\mathrm{S}$ dollars out for $\mathrm{T}$ years will be given by equation (1). The term $t_{\mathrm{F}} t_{\mathrm{S}}$ appears because state income taxes can be deducted when filing federal income taxes; this term would not appear for nonitemizers.

$$
V(T)=S \cdot\left[1+\left(1-t_{F}-t_{S}+t_{F} t_{S}\right) r_{M}\right]^{T}
$$


Second, consider putting all available funds into the SESP immediately. In this case none of the returns in the plan will be subject to any state or federal taxes. We have a very simple compounding problem for the $\mathrm{S}$ dollars earning a net return of $r_{S}$ for $T$ years. In addition we must account for the gains due to the state deduction. Here we get that state deduction only in the first year, but we also earn interest in the future years on that tax savings. We assume this tax savings has been placed into a taxed account. Equation (2) calculates the dollar amount available to an itemizing investor after $\mathrm{T}$ years if they place S dollars into the SESP now. Notice that the value of the immediate tax savings depends not only on the size of the allowable deduction, $\mathrm{D}$, but also on the state tax rate, $\mathrm{t}_{\mathrm{s}}$, and the federal tax rate, $\mathrm{t}_{\mathrm{F}}$, for those who itemize. ${ }^{5}$

$V(T)=S \cdot\left(1+r_{S}\right)^{T}+D \cdot t_{S} \cdot\left(1-t_{F}\right)\left[1+\left(1-t_{F}-t_{S}+t_{F} t_{S}\right) r_{M}\right]^{T}$

Third, the investor can spread his contributions to the state plan evenly over the $\mathrm{T}$ years to get the maximum state deduction. Equation (3) calculates the sum available after $\mathrm{T}$ years for those who itemize. This equation has three major terms. The first term handles the yearly contributions that compound tax-fee. Next we have the annual tax savings due to the deduction that will compound over the years at the taxed rate of return. Finally, we have the funds not yet contributed to the plan earning a return in the private market until they are contributed to the state plan.

$$
\begin{aligned}
V(T)= & \sum_{i=1}^{T} D\left(1+r_{S}\right)^{i} \\
& +\sum_{i=1}^{\mathrm{T}} \mathrm{D} \cdot \mathrm{t}_{\mathrm{S}} \cdot\left(1-\mathrm{t}_{\mathrm{F}}\right)\left[1+\left(1-\mathrm{t}_{\mathrm{S}}-\mathrm{t}_{\mathrm{F}}+\mathrm{t}_{\mathrm{S}} \cdot \mathrm{t}_{\mathrm{F}}\right) \cdot \mathrm{r}_{\mathrm{M}}\right]^{\mathrm{i}} \\
& \quad+\sum_{i=1}^{T-1}\left[(S-i D)\left(1-t_{S}-t_{F}+t_{S} t_{F}\right) r_{M}\right]\left\{1+\left(1-t_{S}-t_{F}+t_{S} t_{F}\right) r_{M}\right\}^{T-i}
\end{aligned}
$$

\section{Results for Various Investors}

Consider a Michigan couple with $\$ 50,000$ to invest over the next five years. Michigan's maximum annual deduction equals $\$ 10,000$ per couple. This plan offers several options so that the couple should be able to match the private market rate of return. We shall assume that the annual rate of return will be 5\%: $r_{S}=r_{M}=0.05$. This Michigan couple faces a flat $4.1 \%$ state tax rate. First, we shall assume that they lie in the $25 \%$ federal tax bracket, and that they itemize their deductions. ${ }^{6}$ If the couple ignores the state plan and puts their funds into the market, equation (1) applies: this couple will have $\$ 59,661$ in 5 years. Either state savings plan strategy will improve on this outcome. Equation (2) tells us that this couple will have $\$ 64,181$ in 5 years if they put the whole $\$ 50,000$ into the state plan immediately. See Table 1 . This couple will do somewhat worse if they choose the third strategy of contributing $\$ 10,000$ to the plan each year. Equation (3) shows us that this couple will end with $\$ 63,732$, $\$ 449$ less than contributing all of $\mathrm{S}$ to the state plan now.

Although contributing all to the state fund now appears to be the winning strategy, this choice is sensitive to the federal marginal tax rate. If the couple had been in the $10 \%$ bracket, choosing the maximum annual deduction has a $\$ 750$ advantage over the contribute-all-now strategy: $\$ 65,020$ to $\$ 64,270$. Given their rather short investment time and their modest federal tax rate, this couple gains more from the state deduction than escaping federal taxes. Similarly, if our family finds itself at the highest federal income tax rate of 35\%, then choosing to place all of their funds into the state plan will lead to over $\$ 1200$ more than the annual contribution, $\$ 64,125$ compared to $\$ 62,900$. The advantage of compounding returns at a tax-free rate rises for those in higher tax brackets. 
Table 1 shows that someone with $\$ 100,000$ to invest over 10 years will wish to contribute all the money now no matter what positive federal tax rate they face. Those in the $10 \%$ bracket gain about $\$ 1200$ dollars, but the gain rises to almost $\$ 11,000$ for those in the $35 \%$ bracket. Table 1 also reveals that those with $\$ 180,000$ to invest over 18 years do substantially better when they contribute all now rather than contributing $\$ 10,000$ annually. ${ }^{7}$ Someone in the $25 \%$ bracket ends up with $\$ 46,562$ more by contributing all to the state plan now, $\$ 433,772$ compared to $\$ 387,210$. Notice also that these investors will be nearly $\$ 100,000$ better off than those who do not participate in any plan.

Table 1: Value in T Years 5\% Rate of Return 4.1\% State Tax Rate D = \$10,000 Itemize Federal Tax Return

\begin{tabular}{|c|c|c|c|}
\hline Federal Tax Bracket & No State Plan & All S into Plan Now & Contribute D Annually \\
\hline \multicolumn{4}{|c|}{$\mathrm{S}=\$ 50,000$ and $\mathrm{T}=5$} \\
\hline $10 \%$ & $\$ 61,761$ & $\$ 64,270$ & $\$ 64,020$ \\
\hline $25 \%$ & $\$ 59,661$ & $\$ 64,181$ & $\$ 63,732$ \\
\hline $35 \%$ & $\$ 58,293$ & $\$ 64,125$ & $\$ 62,900$ \\
\hline \multicolumn{4}{|c|}{$\mathrm{S}=\$ 100,000$ and $\mathrm{T}=10$} \\
\hline $10 \%$ & $\$ 152,577$ & $\$ 163,452$ & $\$ 162,244$ \\
\hline $25 \%$ & $\$ 142,377$ & $\$ 163,327$ & $\$ 156,124$ \\
\hline $35 \%$ & $\$ 135,923$ & $\$ 163,252$ & $\$ 152,309$ \\
\hline \multicolumn{4}{|c|}{$\mathrm{S}=\$ 180,000$ and $\mathrm{T}=18$} \\
\hline $10 \%$ & $\$ 385,081$ & $\$ 433,981$ & $\$ 415,229$ \\
\hline $25 \%$ & $\$ 339,989$ & $\$ 433,772$ & $\$ 387,210$ \\
\hline $35 \%$ & $\$ 312,751$ & $\$ 433,655$ & $\$ 370,642$ \\
\hline
\end{tabular}

Most investors in Michigan (and states with similar savings plans and tax rates) will do better by contributing all of their money to the state plan now. Only those facing both shorter time horizons and lower federal tax brackets will find the maximum annual contribution scheme desirable. ${ }^{8}$ This result might change, however, if one lived in a state with a higher marginal tax rate.

State marginal tax rates can reach much higher than Michigan's flat 4.1\%. Many states have upper brackets in the 8 to $9 \%$ range, such as California, Iowa, Maine, New Mexico, North Carolina, and Oregon: see Federation of Tax Administrators (2003). Montana has the highest top-bracket rate at 11\%. A deduction from state income will mean much more to a high-income person in one of these states than in Michigan. Our calculations, however, will not help decision makers in all of these states. Since California does not allow a state deduction, its residents should put all of their money in the plan now. Since New Mexico places no limit on the annual contribution (other than the overall contribution limit), its residents should also put in all the money now. A resident of Iowa, however, faces an $8.98 \%$ upper bracket and an annual $\$ 2180$ contribution limit per account. A resident of New York faces a $6.85 \%$ rate with a $\$ 10,000$ annual limit for joint filers.

For residents in our higher-tax-rate state we shall assume a marginal tax rate of $9 \%$ with a $\$ 10,000$ annual limit. Table 2 presents the results. Contributing the maximum deductible does do better for the $\$ 50,000$ investor over 5 years unless he lies in the top 35\% bracket. Someone in the 10\% bracket makes over $\$ 2912$ more with the annual D contribution, someone in the $25 \%$ bracket makes $\$ 920$ more, but someone in the $35 \%$ bracket makes $\$ 48$ less. An investor with a 10 -year horizon facing only a $10 \%$ federal rate does better by taking the maximum annual deduction. Those 10 year investors facing $25 \%$ and $35 \%$ brackets, however, do better by contributing the full sum to the state plan now, with someone in the highest tax bracket doing substantially better. Not surprisingly the advantage for placing sums into the plan become larger when looking at the much longer 18-year time frame. 
Table 2: Value in T Years 5\% Rate of Return 9\% State Tax Rate $D=\$ 10,000$ Itemize Federal Tax Return Federal Tax Bracket No State Plan All S into Plan Now Contribute D Annually

$10 \%$

$25 \%$

$35 \%$

$10 \%$

$25 \%$

$35 \%$

$10 \%$

$25 \%$

$35 \%$

$$
\mathrm{S}=\$ 50,000 \text { and } \mathrm{T}=5
$$

$\$ 61,111 \quad \$ 64,804 \quad \$ 67,217$

$\$ 59,134 \quad \$ 64,612 \quad \$ 65,532$

$\$ 57,844 \quad \$ 64,491 \quad \$ 64,443$

$$
\mathrm{S}=\$ 100,000 \text { and } \mathrm{T}=10
$$

$\$ 149,382$

$\$ 139,872$

$\$ 164,099$

$\$ 163,834$

$\$ 163,672$

$\$ 166,088$

$\$ 159,268$

$\$ 154,999$

$$
\mathrm{S}=\$ 180,000 \text { and } \mathrm{T}=18
$$

$\$ 370,689 \quad \$ 434,860$

$\$ 329,297 \quad \$ 434,426$

$\$ 304,170$

$\$ 434,180$

$\$ 418,596$

$\$ 390,303$

$\$ 373,462$

One would expect that, everything else equal, the greater the market rate of return the sooner we will wish to move funds to tax-free investments. Table 3 confirms and quantifies this expectation: it contains calculations for investors facing a $10 \%$ rate of return in both our lower and higher tax-rate states. Contributing now dominates in nearly all cases, generally by thousands if not tens of thousands of dollars. Only someone in a low federal taxbracket from a high tax-rate state with a short time horizon will find contributing D annually desirable.

\section{Conclusions}

We have seen that whether one should contribute all of one's money now to a state savings plan or whether to contribute annually the maximum state deduction depends on the state marginal tax rate, the investor's federal tax bracket, when the money will be needed, and the rate of return to investments. All else equal, the investor will wish to place all the money into the state plan soon if the investor lives in a low-tax state, lies in a higher federal taxbracket, faces a longer time horizon, and faces a higher market rate of return. Those with a short-time horizon in a high-tax rate state should consider the maximum deductible option.

Many investors with wealth to make such decisions likely lie in the $25 \%$ tax bracket or higher. Most calculations show that putting the money into the state plan early does better. On the other hand, these plans generally do not limit participation to only parents. A wealthy retired couple may find itself in a low-federal income tax bracket and with a promising grandchild in middle school. This couple could likely find the maximum

\begin{tabular}{|c|c|c|c|}
\hline Federal Tax Bracket & No State Plan & All S into Plan Now & Contribute D Annually \\
\hline \multicolumn{4}{|c|}{$\mathrm{S}=\$ 50,000, \mathrm{~T}=5$, and $\mathrm{t}_{\mathrm{S}}=0.041$} \\
\hline $10 \%$ & $\$ 75,638$ & $\$ 81,084$ & $\$ 80,639$ \\
\hline $25 \%$ & $\$ 70,761$ & $\$ 80,961$ & $\$ 77,939$ \\
\hline $35 \%$ & $\$ 67,652$ & $\$ 80,886$ & $\$ 76,246$ \\
\hline \multicolumn{4}{|c|}{$\mathrm{S}=\$ 100,000, \mathrm{~T}=10$, and $\mathrm{t}_{\mathrm{S}}=0.041$} \\
\hline $10 \%$ & $\$ 228,843$ & $\$ 260,219$ & $\$ 247,975$ \\
\hline $25 \%$ & $\$ 200,283$ & $\$ 259,990$ & $\$ 230,735$ \\
\hline $35 \%$ & $\$ 183,069$ & $\$ 259,862$ & $\$ 220,584$ \\
\hline \multicolumn{4}{|c|}{$\mathrm{S}=\$ 50,000, \mathrm{~T}=5$, and $\mathrm{t}_{\mathrm{S}}=0.09$} \\
\hline $10 \%$ & $\$ 74,115$ & $\$ 81,726$ & $\$ 82,720$ \\
\hline $25 \%$ & $\$ 69,556$ & $\$ 81,465$ & $\$ 79,626$ \\
\hline $35 \%$ & $\$ 66,643$ & $\$ 81,305$ & $\$ 77,682$ \\
\hline \multicolumn{4}{|c|}{$\mathrm{S}=\$ 100,000, \mathrm{~T}=10$, and $\mathrm{t}_{\mathrm{S}}=0.09$} \\
\hline $10 \%$ & $\$ 219,721$ & $\$ 261,154$ & $\$ 249,691$ \\
\hline $25 \%$ & $\$ 193,521$ & $\$ 260,681$ & $\$ 232,334$ \\
\hline $35 \%$ & $\$ 177,654$ & $\$ 260,414$ & $\$ 222,052$ \\
\hline
\end{tabular}
deduction desirable.

Table 3: Value in T Years $10 \%$ Rate of Return $\mathrm{D}=\$ 10,000$ Itemize Federal Tax Return 


\section{Suggestions for further research}

This study has analyzed a fundamental choice faced by investors with a substantial amount of money and a child dreaming of college. Should one put all of one's money into a state savings plan or make even contributions over the years? Further research could open the options to include variations between these two choices. In addition, further study should be done on the desirable timing of withdrawals from these accounts.

\section{Endnotes}

1. Geisel (2002) and Logan (2002) describe the growing popularity of these college savings plans. The major state alternative has been prepaid tuition plans. Under this alternative one contributes a sum of money now based on the age of the child, and the plan guarantees to pay the child's tuition to that state's public. Many prepaid plans have worked out well for parents given the rapid rise in tuition over the past two decades. Unfortunately, many state plans have been getting into financial difficulties in recent years. Consequently some states have backed off their previous guarantees, others have greatly increased their prices, and some have closed their programs to new investors: see Block (2002) and Crenshaw (2002). These prepaid tuition plans have also been less flexible than the state savings plans, where the money can be taken to nearly any college or university.

2. Under certain circumstances one would not want to make an extremely large contribution in one year if the gift tax would apply. For other people these plans can be a useful mechanism to avoid estate taxes. Generally a transfer of more than $\$ 11,000$ means a gift tax form will have to be filed. Actually $\$ 55,000$ can be given tax-free in one year, since the contribution can be treated as though it comes over the following five years. (This limit rises to $\$ 110,000$ for a husband and wife.) Just because a form has to be filed does not mean taxes have to be paid. Given the move to eliminate estate and gift taxes, these taxes will be a problem for only a small percentage of families.

3. We ignore compromise investment schemes between these two choices. An investor could contribute 2D the initial year and nothing in year T-1 for example.

4. In our tables we assume that returns on that first $\$ 40,000$ for a year could compound over the next 4 years at the taxed market interest rate. On further consideration, it would seem desirable to increase our contribution to the state plan by the amount of the tax savings, so that more of our funds would compound tax free, and yet we still would have money from our original sum to make future contributions. When the formulas are modified, the general pattern of results changes little. We have decided to keep the original choice of contributing $\mathrm{S}$ now or $\mathrm{D}$ per year over the next $\mathrm{T}$ years.

5. $\quad V(T)=S \cdot\left(1+r_{S}\right)^{T}+D \cdot t_{S}\left[1+\left(1-t_{F}-t_{S}\right) r_{M}\right]^{T}$ describes the return for nonitemizers, where the immediate tax savings depends only on the deduction and the state tax rate.

6. Only about $1 / 3$ of taxpayers itemize, although the families we discuss here may be more likely to itemize given their higher levels of income and wealth.

7. In calculations for the 18 year example and the 10 year example, we assume that all gains in the state plan will be free of tax. Technically, withdrawals from these plans will be free of federal income taxes only through December 31,2010. We assume that political pressure will lead the federal government to extend these benefits as this date approaches, but certainly there exists a risk that future budget difficulties may lead to no action being taken.

8. This general pattern of results still holds, with small adjustments in dollar amounts for, nonitemizers. Nonitemizers tended to value the maximum state deduction slightly more than did itemizers. For nonitemizers the advantage from having lower state taxes was not partly offset by increased federal taxes due to lower federal deductions.

\section{References}

1. Block, Sandra, "States dropping and changing struggling pre-paid tuition plans," USA Today, December 25, 2002.

2. Burman, Leorard E., William G. Gale, and David Weiner, "The taxation of retirement saving: choosing between frontloaded and back-loaded options," National Tax Journal, Vol. 54, No. 3, pp. 689-702, 2001.

3. Crenshaw, Albert B., "Delays and Price Hikes for Prepaid Tuition." Washington Post, October 20, 2002.

4. Davis, Albert J., "Choice Complexity in Tax Benefits for Higher Education," National Tax Journal, Vol. 55, No. 3, pp. 509-538, 2002.

5. Federation of Tax Administrators, "State Individual Income Taxes," <http://www.taxadmin.org/fta/rate/ind_inc.html $>$, February 18, 2003.

6. Geisel, Jerry, "College Savings Plans are Inexpensive, Popular,” Business Insurance, Vol. 36, No. 14, p. 4, 2002.

7. Logan, Brendan, "Sec. 529 Planning Opportunities," The Tax Advisor, Vol. 33, No. 10, pp. 638-640, 2002. 